\title{
前言: 中国文化民族主义的复兴
}

郭英杰

五四以来曾有过数次文化民族主义的回潮，但六四以来的文化民族主义复兴，即使 算不上二十世纪的高潮, 也是中华人民共和国史无先例的现象。这种现象无疑不是 孤立的, 而是中国社会政治变革的一部分, 没有全面深入的分析便难以看清其真 相。然而，民族主义是个十分容易情绪化的话题，即使力求中立的学者也难做到客 观冷静。因此, 国内对于文化民族主义兴衰的评说，与其他各种民族主义相似，大 多两极分化, 同情者欲其兴, 反对者欲其亡。欲其兴者或夸大其词, 以壮声威, 或 矢口否认文化民族主义的兴起，旨在告诫同道人：“革命尚未成功，吾辈尚需努 力。”欲其亡者也采用类似的策略，目的则是为了提醒人们对这股“逆流”提高警 惕；要么就把它说得微不足道，以免助长了敌人的威风。

对于文化民族主义的兴衰尚且莫衷一是, 对其性质和特点就更难形成一致意见。翻 开有关中国民族主义的文章, 具体的分析固然有之, 更多的则是闭门造车, 是抽象 的是与非, 合理不合理, 明智不明智, 应该如何如何, 不一而足, 到头来却说不清 民族主义为何物, 道不明它欲何为。本来公说公有理, 婆说婆有理, 这倒无可厚 非, 只要自圆其说、持之有据也就是了。怕只怕价值评判一马当先, 而事实反倒不 被当成一回事了。这并不是说学者可以完全不受价值观念的影响, 可以绝对客观公 正，但学术毕竟不同于政治鼓噪或道德说教。

缘此种种，本专辑主要讨论文化民族主义现象，而不关心它应该如何之类的问题。 布庸置疑, 它是一种十分复杂的东西, 绝不是几篇文章就可以概括的, 它的来龙去 脉更难以一言以蔽之。我们的目的无非是抛砖引玉, 试图超越价值观念的论辩, 冲 破门户之见的阻隔，把对中国民族主义的思考进一步引向深入。

为了避免不必要的争论, 首先需要对民族主义的概念作几点说明。第一，民族主义 既有消极的一面, 也有积极的一面, 二者混在一起, 你中有我, 我中有你, 难以分 
开。取其精华去其糟粕之类的说法听起来不无道理, 却不知如何实施。况且, 如果 连精华和糟粕都搞不清楚或达不成统一的意见，取什么去什么无从谈起了。这样说 不是为了一笔勾销“智叟”们为百姓指点迷津的贡献, 只是强调这个问题的复杂及现 象本身的重要。

第二，我们大致同意Anthony Smith1给民族主义所下的定义，既：民族主义是一种 意识形态思潮，它的目标是维持民族自主(national autonomy)、民族认同(national identity)与民族统一(national unity)。其中自主不仅指不受外国或者外族势力的奴 役和统治，还包括“主权在民” ( popular sovereignty) 的诉求。自英国资产阶级革 命和法国大革命以来，这种诉求与民主运动携手并肩，融为一体，冲击了神权和王 权的霸主地位。正是从这种意义上说民族主义才是现代的产物。这样的民族主义不 光前现代中国没有，今天也难说。反美反日情绪之类当然也不能不让叫民族主义， 但称之为“主义”未免抬举它了。这样的“主义”海内外已有大量的评论，因此不作为 我们讨论的中心。再说，类似的东西中国古代早已有之，无现代性可言，而“主权 在民”这一民族主义和民主主义的核心原则却至今难以落实，甚至中国的民主志士 都耻于打出这样的旗号。

第三，民族主义可以分为政治民族主义和文化民族主义两大类。前者以“主权在民” 为出发点，力图实现民族自主自治，建立自己的、与世界其他民族国家平等的主权 民族国家，并维护民族的统一。后者关注的焦点在于民族认同，尤其是文化认同。 虽然它也关心民族统一和自主, 但并不认为国家必不可少; 而且统一和自主也不单 指领土完整和政治自治，还包括民族凝聚力，坚持自身价值和信仰的权利，以及国 家行为与民族意志、传统价值及民间习俗之间的一致性。2

总而言之，在文化民族主义的视野中，民族是一个经长期演变而形成的有机的整 体，它的精华是它独特和“优越”的文明。这种文明包括语言文字、文学艺术、价值 观、民族精神、共同记忆、神话传说等等，有时它主要表现为一种思维和行为方 式、审美观和文化情趣。这一切构成了个人和群体的认知参照系和认同的基础，需 要代代相传。文化民族主义并不认为文明不可变更, 但主张局部或逐渐的调整，它

\footnotetext{
${ }^{1}$ Anthony Smith, National Identity, Reno, Las Vegas and London: University of Nevada Press, 1993.

${ }^{2}$ John Hutchinson, The Dynamics of Cultural Nationalism, London: Allen \& Unwin, 1987.
} 
认为如果一个民族原有的文化道德秩序和价值信仰体系出现紊乱，随之而来的是道 德沦丧，社会失序和民族的衰落。

一般说来，任何民族主义的意识形态都具有政治和文化的内容，二者相辅相成。但 中国五四以来的民族主义却是一个例外，因为它几乎从头开始就患有严重的精神分 裂症。其症状表现在政治民族主义和文化民族主义两股力量分道扬镬，甚至势不两 立。具体地说, 政治民族主义者 (包括五四知识分子、革命党人和共产党人) 欲图 重建国家权威、重塑国民、富国强兵。尽管他们的思路大相径庭, 但一致认为中国 的传统“封建”文化是造成中国落后和软弱的根本原因，理当属于革命的对象，不打 倒“孔家店”，不扫除传统“封建”文化，中国便不得启蒙，不得富强，不能进入现代 和世界现代民族国家之列。这场运动如排山倒海，势不可挡。相比之下，中国的文 化民族主义者逆潮流而动, 且势单力薄, 自然不是对手。于是, 政治民族主义及其 奉行的“反传统主义”长时期占据主导地位。

共产党人忠实地继承了五四“反传统主义”的传统，并在文革时期把它推向了极致。 虽然中共也曾降低过反传统的调子，但其霸权地位从未受到强劲的挑战，这种情况 一直延续到六四前后。六四以后中共在“爱国主义教育”中重提弘扬优秀传统文化与 它对六四的分析有关，在中共看来，六四的起因不仅包括“资产阶级自由化”和“西 化”思潮，还包括由此引发的“民族虚无主义”。因此，新版的“爱国主义”显著增加了 对优秀传统民族文化的弘扬。

中共对传统文化态度的转变使“反传统主义”和“西化派”遭受了沉重的打击，并改变 了政治民族主义和文化民族主义对峙的格局。尽管官方的“弘扬优秀传统文化”有其 自身的实用目的，但却为文化民族主义粉墨登场创造了百年不遇的良机，也为传统 文化的回归大开方便之门。在这样的背景下国内市场上“古典”和历史剧数量剧增， 曲阜和黄帝陵热闹起来了，据说最近还出现了“读经热”。热度如何暂且不论，对文 化民族主义的理解也可以不尽相同，对于“复兴”的提法更可以质疑，但无论如何传 统文化和文化民族主义的境遇已是今非昔比, 不说五四时期, 与《河歾》为主旋律 的八十年代相比, 已是天壤之别了。 
当然, 官方弘扬传统文化只是文化华民族主义复兴的一个前提条件。另外两个原因 可能具有更加深刻的意义。一是过去二十多年中人们时常听到的“信仰危机”和“道德 危机”; 二是所谓“二十一世纪是中国世纪”的预言。从实质上来看，上述“危机”又是 认同的危机。按 Smith 的解释, 这种危机是由传统的合法性危机引发的, 这是因为 民族的自我意识在很大程度上依赖于它自身的传统和价值体系，如果后者的合法性 出现严重问题，那么以此为基础的民族认同就失去了支撑，就不再被自然而然地接 受了。

就中国的具体情况来说, 中华大传统的合法性危机早在五四时期就已经出现，只不 过连绵不断的革命和战争使这种危机显得无足轻重。随着“新中国”的建立，一套社 会主义信仰价值体系取代了传统的信仰价值体系, 往日的臣民、新民、国人又要被 改造成“社会主义新人”, 这项工作成功与否认另当别论，但集体认同的危机大致得 到解决。但是，改革开放时期社会主义信仰的瓦解又导致了中国社会主义小传统的 合法性危机，同时全球化的潮流使之明显加剧，难以在短期内消失。

八十年代的“西化论”、“国学热”，九十年代有关“人文精神”的讨论、“文化重建”和重 构中华性的呼吁、后殖民批评的流行、“孔子热”、“炎黄热”，以及最近的“读经 热”，似乎都流露出修补或重建群体信仰价值体系的欲望。就连胡锦涛主席构思的 “和谐社会”也要求重建“社会主义核心价值体系”。谁也无法料定中国最终会出现一 个什么样的民族价值体系, 但至少可以看出传统文化没有被排除在外, 而是被当作 可资利用的资源。

这一历史性的转折无疑还受益于有关“中国世纪”的预言以及对于中国未来在全球范 围内进行政治、经济和文化竞争的考虑。文化的竞争不仅包括文化产业的角逐，更 重要的是“软实力”的较量。而“软实力”的竞争远不是一时一地谁胜谁负的问题, 它 关系到谁占据全面的话语权, 谁的价值观念正确合理, 谁的思维、表达和行为方式 可取, 等等。赢家不废举手之劳便可以得到大量的优势, 而输家则要做出巨大的努 力去调整和改变自己的行为举止, 否则就难以被对方所接受, 难以与之对话和交 往。更不用说这样的文化大势对人们的自尊心、自信心和自身价值的影响了。

那么中国用什么样的文化传统、思想、观念和价值来提升自己的“软实力”呢? 也许 在传统文化当中比在“社会主义先进文化”当中更容易找到让世人接受的价值观念。 
与其让历史唯物主义、“四项基本原则”和“雷锋精神”走向世界，还不如谈谈“天人合 一”、“和谐社会”或“和谐世界”。况且，中国的“综合国力”也是今非昔比，国人不必 象鸦片战争和甲午海战以后那样锤胸顿足地自我反省, 寻找受辱于人的缘由。相 反，在不少人看来，中国近二十多年里经济的高速增长再次证明了中国人的㙂明才 智和中国文化的优越性。

虽然这样的优越感绝非无懈可击，但它很可能改变了百年来有关传统文化的争论。 随着民族自信的明显增长, 知识精英对传统文化的估价出现了巨大的变化, 于是 “反传统主义”退潮，而弘扬传统文化、挖掘文化资源和寻文化之根的呼吁则日渐响 亮。难怪以往反传统的政治民族族主义者纷纷停止了对传统的批判，甚至开始反思 启蒙和“五四精神”，并谈论“继承优秀传统文化”。其中不仅包括共产党人，还包括 民主志士和持不同政见者。当然，不能因此断定这就是政治民族主义与文化民族主 义的合流，但可以肯定往日以清算传统为手段来实现富国强兵的目的的政治民族主 义已见式微，而既“富国强兵”又继承和发扬传统已成为多数人能够接受的提法。依 此而论，如果说中华民族的集体认同在近现代史上经历了由正及反的过程，而今它 的重新整合看来已经开始了。

本专辑共收集八篇文章，作者都是在澳大利亚执教的学者。在专辑筹备期间曾数次 邀请中国大陆的学者投稿，有的没有回音，有的答应赐稿，可惜最终却未能如愿以 偿。此外还向一些海外学者发出邀请, 均未收到回音。这样一来本专辑的讨论难免 有不少局限，希望专辑面世以后能够引起更多同行的关注，共同切磋，扩大交流， 以便使这项研究更加全面深入。如前所言，我们的目的只在于抛砖引玉，在于共同 探讨。

在编辑过程中, 除了对个别文字和书写格式作了有限的变动和统一处理, 所有的文 章都保存了原貌, 文章的观点和看法事先没有统一的要求, 事后也不强求统一。这 样做的好处是可以使作者真正畅所欲言，各叙己见；缺点是专辑的整体一致性因而 打了折扣。好在专辑毕竟不同于专著，但愿读者不会求全责备。

可喜的是，作者大都对文化民族主义保持客观冷静的态度，并注重实事求是。陈兆 华从康晓光的《文化民族主义论纲》和杨振宁、王蒙、许嘉璐等人的《甲申文化宣 言》入手，对文化民族主义作了总体的概括，并对其指导思想进行了缜密的分析。 
孔书玉的文章针对电视剧《雍正王朝》和《汉武大帝》的主题内容及其意识形态指 向，深入讨论了历史正剧如何重写民族历史、如何再造民族英雄，以及各种社会力 量如何借助大众文化参与民族重构的话语。王一燕则把视线投向当代中国小说中的 故乡的文学构建，她指出：“无论'中国”被如何设定，无论国族身份设立在乡村还是 市井，叙述中国必然是讲述中国文化传统，而传统又需要建筑在本土场域，即故乡 之中。”

传统和故乡也是李侠一文关注的中心问题, 只不过二者在人们的脑海里变得更加模 糊，而且人们的感情也不无矛盾。通过对《都市风流》和其他都市小说的分析，作 者揭示了中国大规模的城市化所导致的人的离异和失落感; 同时，在都市寻找希望 和梦想, 对千百万人来说, 又有一种不可抵抗的诱惑力。这种失落感也许算不上文 化民族主义，却能够激发人们对日益丧失的“精神家园”的向往。

郑怡的话题同样是围饶文学展开的，但重心不在小说，而是“由余秋雨为始作佣者 的文化散文”。她所关注的首要问题是文化散文写作行为中对当代差异性文化品位 的塑造, 其次, 她仔细地勾勒出通过对过去国族精神家园的改写来重塑当今文化民 族情感的尝试, 并且厘清了文化散文这种新公共话语先锋、国族精神家园及文化民 族情绪在华夏民族重塑过程中所起的作用及其相互关系。

高默波的文章以电视剧《施琅大将军》为重点, 但论及许多民族主义的敏感话题， 如汉奸和民族英雄、夏夷之辩、王朝正塑、立德立功、文攻武卫等等。这不仅使文 章内容丰富多彩，同时还展示了文化民族主义的复杂性，以及文化民族主义复兴所 面对的难题。在作者看来，除非西方的发展和现代化模式彻底破产，除非中国能为 人类现代化发展提供新的模式，否则中国文化民族主义的复兴就不能摆脱困境。

相比之下, 古德曼对文化民族主义的复兴持更加谨慎的态度。他虽然没有对此直接 发表意见，但明确质疑“文化”和“中国文化”等概念的实用性以及文化决定论的社会 发展观，并强调“中国文化”的区域性与共社会经济变革的区域性动因。从这种角度 来看, 难以把中国经济的高速发展归结为文化因素, 因此文化民族主义复兴的口号 便失去了一条重要依据; 另外, 究竟什么是“中国文化”，究竟弘扬什么，这些问题 远比喊口号的人所想象的更加复杂。正如高默波所说，“中国文化”是仁、义、礼、 智、信、忠、孝、节? 还是道教、佛教、穆斯林或其他文化? 
冯崇义对民族主义的批判最为直接了当, 他站在自由主义的立场上, 指出民族主义 妨碍民主化，危害国家利益，危害人权。毫无疑问，本文所说的民族主义大体属于 政治民族主义，甚至包括不少国家主义的成份，当然也包括部分文化民族主义的因 素。作者之所以没有把这三股思潮区别对待无疑是因为它们之间的差别不大，依此 而论，对民族主义的批判自然包括对文化民族主义的批判。这种自由主义的批判免 不了有商榷的余地, 但它却说明自由主义的确是文化民族主义复兴的一大障碍。正 如五四时期一样，在目前新一轮的民族认同论战当中，二者还有一搏，但自由主义 者已经不站上风了。

出版华语专辑是 Portal 在线期刊的总编 Paul Allatson 博士首先提出来的，筹备工作 自始至终得到他的大力支持。Wayne Peake 博士负责日常联络工作并提供具体技术 支援。参与审稿的海内外同行百忙中抽出不少时间仔细阅读稿件并提出详细的修改 意见。悉尼科技大学博士候选人奚平更是不厌其烦, 作了大量细致的编辑工作。在 此一并致谢。尤其感谢各位作者，他们的真识卓见使我受益不浅，相信读者也会有 同感 , 他们的友好合作更加感人至深。

郭英杰

郭英杰博士在澳大利亚悉尼科技大学国际研究学院任教, 其主要研究项目包括当代 中国的民族主义和中国入世以来的对内开放政策。近著有 Cultural Nationalism in Contemporary China: The Search for National Identity under Reform。 